\title{
Probabilistic seismic damage assessment of reinforced concrete buildings considering directionality effects
}

Yeudy F. Vargas Alzate, Lluis G. Pujades Beneit, Alex H. Barbat, Jorge E. Hurtado Gomez, Sergio A. Diaz Alvarado \& Diego A. Hidalgo Leiva

\begin{abstract}
Most of buildings and structures are usually projected according to two main axes. However, the geographical position of these buildings varies randomly. Such random distributions of the azimuthal positions of structures, in most of the cities, generally, are not accounted for when assessing their seismic risk; certainly, the direction of the seismic loads is another highly random variable. Moreover, an additional important source of uncertainty is related to the structural response, mainly due to the random character of the mechanical properties. There is a consensus that uncertainties must be considered for adequately assessing the seismic risk of structures, but these directionality effects have not been deeply explored so far. In this article, the influence of the high uncertainty involved in these input variables on the expected seismic damage is analysed. Thus, an actual earthquake, which affected the southern part of Spain, is studied. Notably, damages on a group of affected buildings, located close to the epicentre, are analysed and discussed in detail. The results show that the influence of the random azimuthal position of structures is an important source of uncertainty and that it should be taken into account when estimating the expected seismic risk in urban areas.
\end{abstract}

\section{Introduction}

In the seismic risk assessment of buildings two main random variables are involved, namely the vulnerability of the structure and the seismic action. The uncertainty related to the former depends on the mechanical properties of the materials, the weight supported by the structure and the participation of the non-structural elements, among others. The uncertainty of the latter depends on the fault mechanism, the soil conditions, among many other factors. Even if the seismic action is well known, for instance, in the case that the earthquake has occurred and an acceleration record is available, there is another source of uncertainty related to the random azimuthal position of buildings and the directionality of the acceleration time histories produced by an earthquake. It means that, due to topographical and geological conditions and the construction practice of the urban areas, among many other factors, it is difficult to establish how the acceleration runs into the buildings of a studied area. Reyes and Kalkan (2015), Kalkan and Reyes (2015), Torbol and Shinozuka (2012), Lagaros (2010), Rigato and Medina (2007), López, Chopra, and Hernandez (2000), López and Torres (1997), among others, have studied the influence of the angle of seismic incidence on the structural response. They have found that the seismic response of a structure significantly varies depending on the rotational angle of the acceleration record.

Several simplified methodologies based on static procedures have been developed for assessing the expected seismic damage of buildings (Freeman, Nicoletti, \& Tyrell, 1975; Freeman, 1998; Fajfar \& Gašperšič, 1996; Chopra \& Goel, 1999; Fajfar, 1999). These methodologies are based on the assumption that the behaviour of the building is governed by the first mode of vibration. In the case of tall or asymmetric buildings, further consideration should be made by taking into account the effects of higher modes in elevation (Chopra, Goel, \& Chintanapakdee, 2004; Poursha, Khoshnoudian, \& Moghadam, 2009), in plan (Chopra \& Goel, 2004; Bento, Bhatt, \& Pinho, 2010; Bhatt \& Bento, 2011) or in both, plan and elevation (Kerslin \& Fajfar, 2012; Reyes \& Chopra 2010, 2011; Fujii, 2011).

Tools for seismic risk assessment in urban areas in the U.S. (e.g. Hazus) and in Europe (e.g. EURisk) used these approaches in which building damage is estimated from response spectral 
ordinates. Some examples of the application of these simplified approaches to evaluate the seismic risk of urban areas can be found in Barbat, Pujades, Lantada, and Moreno (2008), Lantada, Pujades, and Barbat (2009), Pujades, Barbat, González-Drigo, Avila, and Lagomarsino (2012), Vargas, Pujades, Barbat, and Hurtado (2013), González-Drigo et al. (2013). Notice that such simplified approaches consider the non-linear structural seismic response of structures by means of bilinear capacity curves and the seismic hazard by means of acceleration spectra commonly obtained from a PSHA, Ordaz and Aguilar (2015). However, in some cases, due to the height and to the irregularity in plan or elevation of a building, it is difficult to simulate a reliable seismic response of a structure by means of a capacity curve. In these cases, it is necessary to assess the expected seismic damage by performing non-linear dynamic analysis (NLDA) instead of pushover analysis. It is well known that the computational effort involved when applying NLDA in a stochastic way requires a great deal of time to run the analyses, making the process extremely time-consuming. However, the increasing capacity of current processors combined with adequate simplifications in the structural modelling makes feasible the use of NLDA to appraise the seismic risk of structures.

In order to analyse the influence on the structural response of the variables described above, in this article, the seismic damage of a group of buildings located in the San Fernando neighbourhood of the city of Lorca, Spain, which were affected by an earthquake occurred in May 2011 , is calculated. The non-linear dynamic response of the buildings, including the uncertainties related to the mechanical properties of the materials and the directionality of the earthquake are considered. On the one hand, the mechanical properties considered as random are the yield strength of the concrete and the yield strength of the steel. Other variables such as the elastic modulus of the materials and the shear capacity of the elements, among others, also are treated indirectly as random variables because they are calculated by means of formulas proposed in the literature relating the corresponding yield strengths to these mechanical properties. Moreover, a study of the spatial variability of the mechanical random samples generated is conducted too. Based on this study, a new approach for considering the spatial variability, by taking into account the correlation between the samples generated for the strength of the concrete is proposed. On the other hand, the influence of the incidence of the accelerations produced by an earthquake is also investigated. It is important to recall that, in the present work, other sources of uncertainties of the seismic action have not been considered because the parameters of the failure mechanism and the recorded acceleration are known. It is worth to mention that buildings studied in this article, which were built using the same blue prints, were actually damaged by the earthquake at very different damage levels. This fact was the motivating concern and the starting point of the present work; it is worth noting that the results obtained and presented herein show a good agreement between the observed and simulated damage. Thus, this allows concluding that the proposed approach provides an improved numerical tool, which can be useful to predict the expected seismic damage of structures.

\section{The Lorca, May 2011 earthquake}

The 2011 Lorca earthquake was a moderate magnitude 5.1 $\mathrm{M}_{\mathrm{w}}$ earthquake that caused significant localised damage in the Region of Murcia, Spain. This earthquake caused nine casualties and relevant economic losses. The epicentre was located at the Alhama de Murcia fault, near the town of Lorca. Notice that, despite the moderate magnitude of the earthquake, a large number of civil structures were damaged. This fact highlights the high seismic vulnerability of several structures, located in areas with low-to-moderate seismicity, which have not been generally projected to withstand earthquakes. The main issues related to the Lorca earthquake can be found in González, Tiampo, Palano, Cannavó, and Fernández (2012), Rueda, Dreger, Garcia Blanco, and Mezcua (2014) and Alarcón and Benito Oterino (2014). Maximum peak ground acceleration (PGA) values recorded in Lorca, in the horizontal components, were $.153 \mathrm{~g}$ and $.365 \mathrm{~g}$, respectively. The vertical 
ground motion had a PGA of $.117 \mathrm{~g}$. These high PGA values were mainly a consequence of the shallow depth of the focus and of the proximity of the earthquake, whose epicentral distance was about $4.6 \mathrm{~km}$. Then, these values decay with the distance as predicted, in general, by the motion attenuation models. Figure 1 shows the three components of the acceleration recorded in the Lorca station.

\section{Case study: the San Fernando neighbourhood}

Among the many structures damaged by this earthquake, a special case reported is the San Fernando neighbourhood. Its singularity is due to the fact that buildings belongings to the neighbourhood were built using the same structural blueprints. However, some of these buildings were strongly damaged by the earthquake, but it is relevant to say that some of them were not damaged at all. Notice that also moderate damaged buildings were also reported, i.e. the damages of these buildings were repairable.

Information about the seismological station, the recording site and the San Fernando neighbourhood is shown in Table 1. Figure 2 depicts the location of the epicentre (Ep), station (St) and studied buildings (Bld). Note that epicentral azimuths and distances are quite similar for the accelerometric station and for the San Fernando neighbourhood, being the distance between the station and the neighbourhood no more than $1.6 \mathrm{~km}$. Concerning soil conditions, previous works established that station and building were located on stiff soils with vs30 of about $800 \mathrm{~m} / \mathrm{s}$ (Navarro, García-Jerez, Alcalá, Vidal, \& Enomoto, 2014). However, site effects within the San Fernando neighbourhood would require extensive site characterisation which is out of the scope of this article.

\subsection{Description of the buildings}

The buildings of the San Fernando neighbourhood have five stories and are composed of reinforced concrete elements. The age of the buildings was 35 years at the time of the Lorca earthquake. Due to the antiquity of the structure and to the construction details, it can be concluded that buildings were designed and constructed without considering any seismic design regulation. A picture of a typical building of the neighbourhood can be seen in Figure 3.

Figure 3 also shows that the first floor has not masonry infill. This common type of irregularity generally contributes to increase the vulnerability of structures. In fact, most of the damage observed in these buildings was located in columns of the first floor. In upper floors, masonry enclosures and partition walls are mainly made of typical clay units. Cross sections of the structural elements, according to the original blueprints, are shown in Figure 4. The height of the building is $13.25 \mathrm{~m}$ and, in plant, the building is contained in a rectangle of dimensions 30 and $17.5 \mathrm{~m}$. However, as is shown later in the description of the model, the typical building presents two symmetric openings.

\subsection{Observed damage}

$\mathrm{n}$ the San Fernando neighbourhood, there were isolated and compound buildings; compound buildings were made of two or three side by side individual edifices, being each edifice as the one modelled herein. It is worth to note that no significant pounding effects, contributing to damage, were reported; this fact can be attributed to a coherent vibration of individual near buildings. In our view, the damage was mainly due to a soft first floor effect.

Figure 5 displays an aerial view of the buildings of the San Fernando neighbourhood. In this image, buildings have been marked according to the damage caused by the earthquake. Notice that damage levels have been estimated according to expert opinion. Green colour indicates that the building was not damaged; yellow colour means that the damage is reparable and red colour refers to those buildings that were most damaged. These different damage grades will be 
explained herein by considering the uncertainties associated with the mechanical properties of the materials and, chiefly, the effect of the directionality of the seismic action due to the earthquake. To do so, a structural 3D frame model will be made based on the original blueprints of the buildings. These blueprints contain information on the geometry of the building, on the cross section of the structural elements and on the characteristic strength of the materials. Then, a series of NLDA are performed and damage indices are calculated from the dynamic response of the structural model. Moreover, the damage calculated will be compared with the observed damage described above.

\subsection{Modelling considerations}

In typical older reinforced concrete frame members, flexure, shear or combined flexure and shear failure may develop in sections called critical regions. That is because older buildings have many structural deficiencies as, for instance, lack of sufficient longitudinal and transversal reinforcement in critical regions and/or inadequate size of cross sections, among many others. For these reasons, in critical regions, failure in flexure, shear or combined shear flexure is likely to occur. This kind of failures were presented in several structural elements of the buildings located in the San Fernando neighbourhood. For instance, Figure 5 also shows some damaged columns at the ground floor. Some columns exhibited fail in shear and fail in flexure. Therefore, to model the behaviour of the buildings at the San Fernando neighbourhood, a frame element, where its non-linear behaviour is concentrated at both ends, Sharpe (1974), has been used. In addition, to take into account the non-linear behaviour in flexure and in shear, two types of plastic hinges have been considered at both ends of the frame elements. It is worth noting that shear hinges depend on flexural hinges. To do so, when a plastic hinge appears, in a critical region, due to inelastic flexural rotation, shear yield strength decreases. This way, when a flexure hinge occurs, the probability occurrence of a plastic hinge due to shear increases. As well, notice that, in critical regions, shear hinges may appear without the need for a flexure hinge. Further details on the interaction process between flexural and shear hinges can be found in Ruaumoko manuals, Carr (2000). Figure 6 shows a function for reducing the shear strength due to inelastic flexural rotation, while $\mu 1$ and $\mu 2$ are related to the initial and ultimate ductility due to inelastic flexural rotations, respectively.

Thus, to consider the hysteretic cycle for flexure-failing mechanism, the modified Takeda hysteresis law, Otani (1974), has been used. Besides, to include the hysteretic cycle for shearfailing, the Sina hysteresis law, Carr (2000), has been considered. Then, by using the aforementioned elements, the structural model has been created based on the original blueprints. Figure 7(a) shows a plant view of the structural model. It is important to mention that the axes shown in Figure 7(a) are used subsequently, as reference, for measuring the angle of rotation of the acceleration records. Figure 7(b) depicts a 3D view of the building model. Further assumptions in the modelling are as follows: (i) the static loads acting on the structure follow the recommendations of Eurocode 2, CEN (2004), for reinforced concrete structures; (ii) the Rayleigh model is used to consider the damping of the structure; (iii) slabs elements were modelled as shell elements with a linear elastic behaviour; (iv) masonry panels were modelled as shell elements with a linear elastic behaviour. Notice that no damage was observed neither in slabs nor in masonry panels. The software to perform the analysis is RUAUMOKO 3D (Carr, 2000).

\subsection{Local and global damage indices}

As mentioned above, in this article, for estimating numerically the nonlinear dynamic response of the building modelled, the NLDA is used. From the output of an NLDA, if some element exhibit non-linear behaviour, the damage index of Park and Ang can be calculated, Park and Ang (1985). This damage index is calculated at element level using the following equation: 


$$
D I_{\mathrm{E}}=\frac{\mu_{m}}{\mu_{u}}+\frac{\beta E_{h}}{F_{y} \mu_{u} \delta_{y}}
$$

where $\mu_{m}$ and $\mu_{u}$ are the maximum and ultimate ductilities, respectively, and the subscript E stands for the element-level damage index; $\beta$ is a non-negative parameter which considers the effect of cyclic loading on the structural damage; $E_{h}$ is the dissipated hysteretic energy; $F_{y}$ is the yield load and $\delta y$ is the yield displacement.

The global damage index of the structure, $D I$, is the weighted mean of the local damage presented in the elements, in which the weights are the ratios of the hysteretic energy, dissipated by each element, to the total hysteretic energy dissipated by the entire structure (Park, Ang, \& Kwei-Wen, 1985):

$$
D I=\sum_{i} \lambda_{i} D I_{\mathrm{E}}
$$

As an example of the calculation of the damage index of Park and Ang, the column described in Figure 4(a), which correspond to a typical column of the first inferior levels of the San Fernando buildings, is subjected to the horizontal cyclic displacement history presented in Figure 8.

Figure 9 depicts the hysteretic response of the column presented in Figure 4(a). From this figure, the ultimate ductility, $\mu_{u}$, can be calculated. $\mu_{u}$ is the ductility that may reach the section analysed prior to reach an unacceptable damage level. This unacceptable damage level is related to a strength reduction equal to $80 \%$ of the maximum strength reached by the element. From Figure 9 it can be inferred that, for the analysed element, $\mu_{u}=2.6$. Moreover, the hysteretic energy dissipated at this point is about $E_{h}=3.3 \mathrm{kN}-\mathrm{m}$. Analogously, for beam-type elements the same interaction process used for columns was considered between flexural and shear hinges. However, the ultimate ductility estimated for beams is $\mu_{u}=3$. In this way, when a critical region of the building model reaches a maximum ductility and its dissipated hysteretic energy is obtained, the damage index of Park and Ang, at element level, can be calculated. Vargas, Pujades, Barbat, and Hurtado (2012) used the damage index of Park and Ang to calculate damage curves for reinforced concrete buildings by considering uncertainties. They have found results consistent with the expected seismic damage for the studied structural typology.

\subsection{Uncertainties related to the mechanical properties of the materials}

Another important source of uncertainty affecting the seismic response of a building is associated to the random character of the mechanical properties of the materials. Such effect has been studied by Vargas et al. (2013) which considered the compressive strength of concrete, $f c$, and the tensile strength of steel, $f y$, as random variables. In this article also $f c$ and $f y$ are considered as explicit random variables. The characteristics values shown in Table 2 are considered, for $f c$ and $f y$; these values were taken from the original blueprints. Gaussian probability distributions were assumed for the material properties. Data on the original blueprints was used to calculate the expected values defining the mean values of the random variables. Coefficients of variation were set to $10 \%$.

Also notice that, in the considerations of the uncertainties assumed in this article, the variability of several structural variables is implicitly taken into account, as they are functions of the explicitly simulated random variables. For instance, the elastic modulus of the concrete, $E c$, is related to $f c$ by the equation $E c=4500 f_{c}{ }^{1 / 2}$, and the elastic modulus of the steel, $E s$, is related to $f y$ by the equation $E s=f y / .0021$. It is also worth to mention that, in addition to other independent mechanical parameters, the shear strength is calculated by means of functions depending of the random explicit simulated variables $f c$ and $f y$; these equations can be found in Satyarno (2000). 
Another important aspect to be considered when generating random samples of the mechanical properties of the materials is their spatial variability. This problem is related to the grade of correlation that should exhibit the random samples simulated for the structural model (Franchin, Pinto, \& Rajeev, 2010). The study of the spatial variability aims at improving the quality of the random samples generated. In this article, two extreme assumptions on this issue are analysed. Moreover, a new proposal for considering the spatial variability is proposed.

\subsubsection{Hypothesis of total and null correlation}

To analyse the spatial variability, at a first stage, two extreme cases of correlation are considered; namely, the total correlation and the null correlation. In the case of the total correlation, it is assumed that all the structural frame elements of the building, i.e. simulated columns and beams have the same mechanical properties. That is, in order to perform a Monte Carlo simulation based on $n$ calculated structures, it is enough to generate $n$ random samples of $f c$ and $f y$. In the case of null correlation, it is assumed that the correlation between the mechanical properties, corresponding to samples of frame elements, is null. Then, for each Monte Carlo simulation, it is necessary to simulate as many independent random samples as columns and beams has the building.

Thus, in order to analyse the influence of the total and null hypotheses of correlation in the seismic response, 1000 NLDA are performed for each case. However, in order to simplify the explanation on the spatial variability hypothesis, a 2D frame model is created, from the original blueprints of the San Fernando neighbourhood buildings. Besides, for this calculation the influence of the infill has not been taken into account and only flexure hinges have been considered. Figure 10 shows the frame of the building selected to create the 2D model. The input to perform the NLDA's is the N30W component of the Lorca Earthquake.

The 2D model created has 50 columns and 45 beams. On the one hand, in order to generate random samples based on the total correlation, it is just necessary to generate 1000 samples of $f c$ and $f y$; it can be stated that the correlation of the data for each analysis is total as the generated sample is the same for all the structural elements. On the other hand, in order to generate random samples for the null correlation case, 95,000 independent samples should be simulated and, for each run, one different sample is assigned to each structural element.

Figure 11 reveals significant differences between the considered hypotheses. For the total correlation case, the scattering and the correlation between the damage index and the displacement at the roof is higher than for cursive correlation one. A higher scattering was expected because supposing that all of the structural elements have the same mechanical properties, despite the fact that this is not a realistic assumption, implies to admit that all the structural elements may simultaneously exhibit extreme values. The latter consideration leads to extremely resistant as well as to extremely weak cases. It is worth noting that most of the seismic design codes prescribe the use of characteristic values by reducing the strength of the materials with a coefficient. Note that this pseudo-probabilistic approach may lead to extremely conservative results.

Another important aspect affecting the results is the correlation between the damage index and the displacement at the roof, which is higher in the case of total correlation than in the case of null correlation. It seems more reasonable a low correlation because of the non-linearity of the structural response. For these reasons, it is concluded that the null correlation hypothesis is more adequate than the total correlation hypothesis. Nonetheless, in the case of concrete, the supposition that the strength of the structural elements is completely independent is not realistic because, generally, in the construction process of buildings, the concrete used for columns of a certain storey proceeds from the same blend. The same observation holds for the beams of a given 
storey. Therefore, it is common to assume that concrete strength of structural elements of same storey tends to exhibit a certain grade of correlation. In this way, the random samples of the strength of the concrete should be generated by taking into account these aspects.

\subsubsection{Proposed hypothesis of partial correlation}

To consider the likely correlation that may exhibit the strength of concrete for the elements of a specific storey, it is necessary to establish a new correlation hypothesis. In this article, the following hypothesis that the correlation between the columns or beams of the same storey decrease with distance is proposed. Thus, the correlation matrix for the strength of concrete simulated samples of one storey is constructed in the following way:

$$
\rho_{i, j}= \begin{cases}i=j & \rho_{i, j}=1 \\ i=j \pm k & \rho_{i, j}=1-\frac{k}{r}\end{cases}
$$

where $k$ is a number related to the position of a beam or a column belonging to the same storey of a 2D framed structure. For instance, for the 2D frame depicted in Figure 10, the column of the first storey numbered as $k=1$, will be the first from left to right, the column numbered as $k=2$, of the first storey, will be the second one going from left to right and so on. $r$ is a coefficient associated to the rate of correlation between adjacent elements. Therefore, the correlation matrix for the columns of the first storey, which contains 10 columns, for a coefficient $r=10$, will be:

$$
\rho_{i, j}(\text { columns })=\left(\begin{array}{ccccc}
1 & .9 & .8 & \ldots & .1 \\
& 1 & .9 & \ldots & . \\
& & 1 & \ldots & . \\
& & & \ldots & .9 \\
& & & & 1
\end{array}\right)
$$

The correlation matrix for the nine beams of the first storey, for a coefficient $r=10$, will be:

$$
\rho_{i, j}(\text { beams })=\left(\begin{array}{ccccc}
1 & .9 & .8 & \ldots & .2 \\
& 1 & .9 & \ldots & . \\
& & 1 & \ldots & . \\
& & & \ldots & .9 \\
& & & & 1
\end{array}\right)
$$

Once the correlation matrix has been defined, the next step is to generate correlated random samples. As a first step, it is necessary to obtain the covariance matrix which is given by

$$
\Sigma_{i, j}=\sigma_{x_{i}} \sigma_{x_{j}} \rho_{i, j}
$$

where $\sigma_{x}$ represents the standard deviation of the random variable $x_{i}$. The next step is to calculate the matrix $\Phi$ which contains the eigenvalues of the matrix $\Sigma$ (see Equation (4)). Subsequently, the covariance rotated matrix $\Psi$ should be calculated by considering the following transformation:

$$
\Psi=\Phi^{T} \Sigma \Phi
$$

The diagonal terms of $\Psi$ contain the rotated variances by taking into account the correlation that exist between the random variables. The squared root of the diagonal terms of the matrix $\Psi$ is the rotated standard deviations: 


$$
\sigma_{y}=\sqrt{\operatorname{diag}(\Psi)}
$$

$\sigma_{y}$ is a vector containing the standard deviations of the random variables in an orthogonal space rotated by considering the correlation matrix. Let $\mu_{x}$ be a vector that contains the expected values of the random variables $x_{i}$. In order to obtain the expected values $\mu_{y}$ in the rotated space, the following equation should be applied:

$$
\mu_{y}=\Phi \mu_{x}
$$

In the sequence, using the rotated expected values, $\mu_{y}$, and the rotated standard deviations, $\sigma_{y}$, the next step consists in generating Gaussian independent random samples which can be stored in the matrix $Y_{i, j}$, being $i=1000$ the number of random simulations, and $j$ the number of random variables. To simulate the random correlated samples of columns, for one storey of the 2D model depicted in Figure 10, $j=10$ and, for beams, $j=9$. Finally, the matrix of random correlated samples is calculated as follows:

$$
X=Y \Phi
$$

In a similar way than the one corresponding to the case of total and null correlation hypothesis, 1000 groups of samples by following the hypothesis of partial correlation are generated and, again, 1000 NLDA have been performed for the structure of Figure 10 subjected to the N30W component of the Lorca earthquake. Figure 12 illustrates the comparison between the damage index of Park and Ang as a function of the maximum displacement at the roof, for the three correlation hypotheses, i.e. total, null and partial correlation. It can be seen that very similar results are obtained when comparing the null and the spatial correlation hypotheses. However, if the mean and the standard deviation for the analysed variables is calculated, i.e. damage index and displacement at the roof, there are slight differences between both hypothesis (see Table 3).

Table 3 shows that the standard deviation of the damage index and the one of the displacements at the roof is higher for the case of total correlation. However, as it was explained above, the latter case is not realistic. The standard deviation for the partial correlation assumption tends to be slightly higher than for the null correlation hypothesis. This was expected because the probability of finding extreme values increases with the level of correlation. Because the hypothesis of partial correlation is more realistic, this assumption has been considered when generating random samples for the concrete strength. Further studies may be conducted in order to analyse how the coefficient $r$ of Equation (3) could be related to the standard deviation of the random dynamic response of buildings.

\subsection{Uncertainties related to the seismic action}

A striking aspect of the main Lorca earthquake record is the important variation of the orthogonal horizontal accelerograms. The horizontal accelerograms shown in Figure 1 exhibit significant differences in both directions. In order to calculate the variation of the magnitude and frequency of the acceleration record, due to the rotation of the horizontal components respect to fixed axes, (for instance, the as-recorded signal axes) the following transformation can be used (Beyer \& Bommer, 2006):

$$
\left(\begin{array}{l}
\ddot{u}_{x(\theta)}(t) \\
\ddot{u}_{y(\theta)}(t)
\end{array}\right)=\left[\begin{array}{cc}
\cos (\theta) & \operatorname{sen}(\theta) \\
-\operatorname{sen}(\theta) & \cos (\theta)
\end{array}\right]\left(\begin{array}{l}
\ddot{u}_{x}(t) \\
\ddot{u}_{y}(t)
\end{array}\right)
$$

Where $\ddot{u}_{x(\theta)}$ and $\ddot{u}_{y(\theta)}$ are the horizontal components of the accelerogram when rotated anticlockwise with an angle $\theta$, while $\ddot{u}_{x}$ and $\ddot{u}_{y}$ are the as recorded accelerograms. This 
transformation allows obtaining rotated accelerograms that can be used, for instance, for analysing the response of a structure, when varying the direction of the acceleration time histories, which may act on it. To quantify how much is the influence of the incidence angle of the Lorca earthquake on the behaviour of structures, it is proposed to calculate the horizontal components of the records, rotated by an angle $\theta$, which varies from $0^{\circ}$ to $180^{\circ}$ by increments of $1^{\circ}$. For each angle, the response spectrum of the rotated record is calculated.

Figure 13(a) shows the acceleration response spectra obtained after rotating the two as recorded horizontal components. In this figure, only the spectra of one component (the periodicity of the spectral accelerations is $180^{\circ}$ ) have been graphed. It is important to note that the variation of spectral accelerations is very high. This fact indicates that the seismic response of a structure, when subjected to an earthquake, strongly depends on its azimuthal angle. Therefore, it is important to include the directionality of the acceleration as a random variable in order to get reliable and accurate results when estimating seismic damage of structures. To get an idea of the large variation due to the horizontal variation of the acceleration record of Lorca, Figure 13(b) shows the relation between the maximum and the minimum spectral accelerations as a function of the considered periods. Notice that, for several periods, these ratios are higher than 7. Thus, the seismic forces acting on the structures of Lorca strongly depended on the azimuthal angle of the buildings. Therefore, the random azimuths of buildings, even having the same structural mechanical and geometrical properties, must be considered when assessing their expected seismic damage. An important issue that can be argued is related to the fact that the San Fernando neighbourhood is not located at the same place where the accelerometric station was; therefore, due to topographical and geological conditions, among others, it is difficult to determine the actual acceleration time histories that really affected the San Fernando neighbourhood. However, as the purpose of this work is to investigate how the San Fernando neighbourhood buildings behave when subjected to the recorded seismic action, it is not considered relevant to exactly know the actual seismic actions at the basement of the buildings.

\section{Probabilistic non-linear dynamic analysis}

The damages observed at the buildings of the San Fernando neighbourhood are analysed herein by considering uncertainties associated to the mechanical properties of the materials and the effect of the directionality of the seismic actions. Firstly, to consider the effect of the random directionality of the loads, the system of axes shown in Figure 7(b) is used. Thus, for an angle $\theta$ equal to zero, the N30W acceleration component acts in the y axis direction, while the N60E one acts in the $\mathrm{x}$ axis direction. Once defined this aspect, a series of non-linear dynamic analysis is performed by considering not only the variation of the angle of the seismic action, but also the uncertainties associated to the mechanical properties of the materials. The vertical component of the ground motion has been included within the analyses too. Then, to quantify the adequate number of samples to properly estimate the uncertainty of the output, the following assumptions have been adopted: (i) the incidence angle of the seismic acceleration varies in the interval $\left[0^{\circ}\right.$, $180^{\circ}$ ) according to an uniform probability distribution; (ii) for each angle, it is assumed that the distribution of the damage index of Park and Ang is Gaussian. Moreover, in order to establish an acceptable number of runs to correctly define this Gaussian distribution, the evolution of its first two moments, that is the mean and the standard deviation values, with the number of samples, was analysed. Figure 14 shows this evolution by using the as recorded $\theta=0^{\circ}$. It was observed that mean values around a value of .55 and standard deviations around a value of .09 were reasonably stable for more than 100 samples (see Figure 14). Thus, this number of a hundred of samples was considered suitable to properly define the expected damage statistical distribution. Thus, as 180 rotation angles have been considered, 18,000 NLDA have been performed. For each NLDA the Park and Ang damage index is also obtained. This way, the first two moments of the assumed Gaussian distribution for each rotation angle are properly defined. Figure 15 shows the 
damage indices obtained as a function of the angle. Mean values and mean values plus/minus one standard deviation are also depicted in this figure. As it can be seen, the expected seismic damage strongly depends on the angle of rotation. Uncertainties associated with the materials properties also induce significant uncertainties in the expected damage indices; notice also that these uncertainties increase with increasing values of the damage index. Since the actual angle of the principal components in the neighbourhood is not known, but the presence of two extreme behaviours (see Figure 5, red and green marked buildings) among several units built with the same blueprints was observed, an hypothesis of the incidence angle equal to $30^{\circ}$ (and its orthogonal pair, $120^{\circ}$ ) was depicted in Figure 15 (see circles red and green) in order to explain the rather different damage states observed in the neighbourhood. In fact, since the buildings were constructed with the same blueprints, the directionality analysis helps explain why four of them suffered intense damage (which corresponds to a damage index higher than .4) and another two, orthogonal to the former, showed no significant damage (as denoted by the green colour). This means that the orientation of the weak axis of the former four buildings made them highly sensitive to the principal component of the earthquake, while the weak axis of the latter two were much less sensitive because their orientation was closer to that of the secondary component of the seismic excitation.

Finally, the damage level of the buildings represented in yellow (see Figure 5), which have either of the two orientations, is explained by the randomness of the mechanical properties, which induce the clustering around middle damage index values, according to the tendency explained mathematically by the central limit theorem of probability theory. Moreover, taking into account the large difference between the principal and secondary components depicted in Figure 13, it is clear that in considering the joint effects of directionality and randomness, as proposed in the present paper, it is perfectly possible to diagnose the presence of these extreme situations.

\section{Discussion of the results}

To analyse the statistical distribution of the expected damage, in an ease way, Figure 16 shows a histogram of the obtained damage indices. The obtained distribution diagram has a bimodal shape. This bimodal form may be attributed to the fact that the expected damage is greater when the seismic action is maximum in the ydirection (short dimension in Figure 5). Moreover, this bimodal condition also may explain why some buildings were more damaged depending on their geographical orientation. Thus, to make a comparison between the observed damage and the simulated one, it may be useful to set damage thresholds. Park et al. (1985) assigned a qualitative description of the damage depending on the value of the damage index. For example, they stated that, if the damage index of a building is greater than .4, its repair cost exceeds the construction cost of the building; for lower damage, repair is economically worthwhile. If the damage index is less than .2, Park et al. (1985) consider that damage is slight, corresponding to sporadic occurrence of cracking. These two damage thresholds, which have been also depicted in Figure 16 with red lines, are important in the analysis of the results because, as it can be seen in Figure 5, some buildings were not damaged at all, while others were strongly damaged, so that demolition was recommended and carried out. If the samples of the histogram of Figure 16 are separated according to the damage thresholds described previously (see the red lines), the percentages of buildings that suffered slight, moderate and extensive damage can be established; it is assumed that extensive damage is not repairable. This analysis is done by counting the number of samples contained in each interval. This count shows that 1954 samples have a DI $<.2,9130$ samples are in the range of $.2<\mathrm{DI}<.4$ and 6916 samples have values of DI $>.4$. Whereas, the overall number of samples is 18,000 , the probabilities of occurrence of each damage state, as defined herein before, are 10.86, 50.72 and $38.42 \%$ for slight, moderate and extensive damage, respectively. It is interesting to note that, in spite of the limited population of buildings in San Fernando neighbourhood, reports on the damage assigned by experts after the 2011 Lorca earthquake (see 
Figure 5) indicate that $13.33 \%$ of the buildings suffered slight damage, while $60 \%$ and $26.67 \%$ had moderate and extensive damage grades, respectively. This good agreement between calculated and observed damage gives support to the obtained result and highlights the importance of taking into account the uncertainties when assessing the seismic risk and vulnerability of structures. In addition, the significant damage variation can be attributed to two factors: (a) the directionality effects, i.e. how very similar buildings are more vulnerable to the same earthquake according to their orientation in space, as explained in the preceding; (b) the randomness of the mechanical properties of the materials. This latter factor helps explaining the differences in damage grade between adjacent buildings with the same orientation, one of which appears in red and the other one in yellow. Notice moreover that there are no adjacent buildings with the extreme damage levels, i.e. red and green. This means that the damage differences among the adjacent buildings can mainly be attributed to the variation in mechanical properties among them. Another important issue is related to the sparseness of the results. In this work, two main sources of uncertainties have been taken into account: (i) the direction of the seismic action and (ii) the mechanical properties of the materials. To assess the contribution to the dispersion of the results, of the uncertainties related to the mechanical properties of the materials, the standard deviations of the samples, at increments of one degree $\left(1^{\circ}\right)$, have been calculated. Notice that, for each degree $\left(1^{\circ}\right)$, approximately 100 samples of buildings were generated. Figure 17 shows the evolution of the standard deviation as a function of the rotation angle. It is worth noting that, for the angles where the standard deviation grows, the mean damage index also does (see Figure 13). For these angles, the acceleration of the horizontal components is higher too. Therefore, as the structure goes into the non-linear range, the system tends to exhibit a more chaotic response.

Finally, the mean value and the standard deviation of the mean values of the damage indices of Figure 13 are .36 and .115 . This uncertainty may be related only to the rotation angles, without consideration of the uncertainties related to the mechanical properties of the materials. Moreover, the mean value and the standard deviation of all the damage indices of Figure 13 are .36 and .13, respectively. This quick calculus shows how the main contribution to uncertainty is due to the directionality effect. However, the good agreement between observed and calculated damage is attributed to the robust considerations of both sources of uncertainty.

\section{Conclusions}

One of the main objectives of the present study has been to analyse the relevance of the directionality effects on buildings of the ground motions due to earthquakes. A special case study of buildings belonging to the same structural typology has been analysed in detail. With this aim, the nonlinear dynamic analysis has been used as a computation tool. Moreover, two kinds of uncertainties have been considered: (i) the uncertainty related to the position of the buildings in terms of their azimuth and (ii) the uncertainty related to the mechanical properties of the materials. As the seismic action was known, it has not been necessary to consider the uncertainties due to the earthquake-to-earthquake variation. Moreover, a correlation study to analyse the spatial variability of the mechanical properties of the materials was conducted; three hypotheses were considered: null correlation, total correlation and partial correlation; it has been concluded that the best hypothesis is that of partial correlation because it takes into account that the strength of the concrete exhibits some correlation, depending on the separation and distance of the frame elements. This correlation assumption has been considered in the sampling of these material properties. About 18,000 NLDAs were performed in order to estimate the statistical distribution of the expected damage. The Park and Ang damage index has been used to quantify the damage level. The key conclusions of this article are, first, that really the expected seismic damage seriously depends on the directionality of the seismic loads and, second, that the observed damage in the San Fernando neighbourhood after the Lorca earthquake shows a very good agreement with the expected one, according to the assumptions taken for the computations. This fact supports the 
appropriateness and robustness of the adopted approach. Besides, from the results obtained, it can be also concluded that buildings belonging to a same structural typology, and even closely located, may exhibit significantly different damage levels which are mainly due to different geographical azimuths of the buildings. Notice that structural modelling has played an important role in the present study. The consideration of the non-linear behaviour of shear, flexure as well as the possibility that shear and flexure mechanisms interact with each other, has led to a sophisticated model, very useful to analyse this specific case study. The obtained results needed a relevant high computation effort, but it is rewarding that the outcome is in agreement with the observed damage. However, it is also important to mention that this high computational cost, may be reduced significantly, if simplified methods, as the one proposed by Pujades, Vargas, Barbat, and González-Drigo (2015), are used. This method allows computing a damage index, which is compatible with the Park and Ang damage index, in a straightforward way, starting from capacity curves. The fact that data of observed seismic damage were available, has allowed the validation of the proposed computational method for the investigation of the directionality effects on expected damages. This manner, robust considerations, not only in structural modelling, but also in adequately taking into account the uncertainties, are a key point to correctly predict the expected seismic damage of structures. Thus, due to the appropriate treatment of uncertainties related to the seismic actions and of the ones related to the mechanical properties of the materials, the results shown in this article can be extended to assess the behaviour, the structural response and the expected damage of buildings of similar typology and/or, even, of those of other typologies.

\section{Acknowledgements}

Diaz-Alvarado S. A. holds a PhD fellowship from the Universidad Juárez Autónoma de Tabasco (UJAT) and from the 'Programa de Mejoramiento del Profesorado, México (PROMEP)'. Hidalgo-Leiva D. A. also holds PhD fellowships from the OAICE, the Universidad de Costa Rica (UCR), and CONICIT, the Government of Costa Rica.

\section{Funding}

This research was supported by the Ministry of Economy and Competitiveness (MINECO) of the Spanish Government; the European Regional Development Fund (FEDER) of the European Union (UE) [project number CGL2011-23621, [project number CGL2015-65913-P] (MINECO/FEDER, UE).

\section{References}

Alarcón, E., \& Benito Oterino, M. B. (2014). Foreword special issue LORCA's earthquake. Bulletin of Earthquake Engineering,12, 1827-1829.

Barbat, A. H., Pujades, L. G., Lantada, N., \& Moreno, R. (2008). Seismic damage evaluation in urban areas using the capacity spectrum method: Application to Barcelona. Soil Dynamics and Earthquake Engineering,28(10-11), 851-865.

Bento, R., Bhatt, C., \& Pinho, R. (2010). Using nonlinear static procedures for seismic assessment of the 3D irregular SPEAR building. Earthquakes and Structures, 1, 177-195.

Beyer, K., \& Bommer, J. J. (2006). Relationships between median values and between aleatory variabilities for different definitions of the horizontal component of motion. Bulletin of the Seismological Society of America,96, 1512-1522.

Bhatt, C., \& Bento, R. (2011). Assessing the seismic response of existing RC buildings using the extended N2 method. Bulletin of Earthquake Engineering,9(4), 1183-1201. 
Carr, A. J. (2000). Ruaumoko-Inelastic dynamic analysis program. Christchurch, New Zealand: Department of Civil Engineering, University of Canterbury.

CEN Eurocode 2. (2004). Design of concrete structures - Part 1: General-Common rules for building and civil engineering structures. Brussels, Belgium: European Committee for Standardization.

Chopra, A. K., \& Goel, R. K. (1999). Capacity-demand-diagram methods for estimating seismic deformation of inelastic structures: SDOF systems. PEER Report 1999/02. Berkeley: Pacific Earthquake Engineering Research Center, University of California.

Chopra, A. K., \& Goel, R. K. (2004). A modal pushover analysis procedure to estimate seismic demands for unsymmetric-plan buildings. Earthquake Engineering and Structural Dynamics,33, 903927.

Chopra, A. K., Goel, R. K., \& Chintanapakdee, C. (2004). Evaluation of a modified MPA procedure assuming higher modes as elastic to estimate seismic demands. Earthquake Spectra,20, 757-778.

Fajfar, P. (1999). Capacity spectrum method based on inelastic demand spectra. Earthquake Engineering and Structural Dynamics, 28, 979-993.

Fajfar, P., \& Gašperšič, P. (1996). The N2 method for the seismic damage analysis of RC buildings. Earthquake Engineering and Structural Dynamics, 25, 31-46.

Franchin, P., Pinto, P., \& Rajeev, P. (2010). Confidence factor? Journal of Earthquake Engineering,14, 989-1007.Freeman, S. A. (1998). Development and use of capacity spectrum method. Proceedings of 6th US National Conference of Earthquake Engineering. Seattle: EERI.

Freeman, S. A., Nicoletti, J. P., \& Tyrell, J. V. (1975). Evaluations of existing buildings for seismic risk. A case study of Puget Sound Naval Shipyard, Bremerton, Washington. Proceedings of 1st US National Conference of Earthquake Engineering. Berkeley: EERI.

Fujii, K. (2011). Nonlinear static procedure for multi-story asymmetric frame buildings considering bi-directional excitation. Journal of Earthquake Engineering,15, 245-273.

González, P. J., Tiampo, K. F., Palano, M., Cannavó, F., \& Fernández, J. (2012). The 2011 Lorca earthquake slip distribution controlled by groundwater crustal unloading. Nature Geoscience,5, 821825 .

González-Drigo, R., Avila-Haro, J. A., Barbat, A. H., Pujades, L. G., Vargas, Y. F., Lagomarsino, S., \& Cattari, S. (2013). Modernist URM buildings of Barcelona. Seismic vulnerability and risk assessment. International Journal of Architectural Heritage: Conservation, Analysis, and Restoration, 9, 214-230.

Kalkan, E., \& Reyes, J. C. (2015). Significance of rotating ground motions on behavior of symmetricand asymmetric-plan structures: Part II. Multi-story structures. Earthquake Spectra,31, 1613-1628

Kreslin, M., \& Fajfar, P. (2012). The extended N2 method considering higher mode effects in both plan and elevation. Bulletin of Earthquake Engineering,10, 695-715.

Lagaros, N. D. (2010). Multicomponent incremental dynamic analysis considering variable incident angle. Structure and Infrastructure Engineering.,6, 77-94.

Lantada, N., Pujades, L. G., \& Barbat, A. H. (2009). Vulnerability index and capacity spectrum based methods for urban seismic risk evaluation. A comparison. Natural Hazards,51, 501-524.

López, O. A., Chopra, A.K., \& Hernandez, J.J. (2000). Critical response of structures to multicomponent earthquake excitation. Earthquake Engineering and Structural Dynamics,29, 17591778 . 
López, O. A., \& Torres, R. (1997). The critical angle of seismic incidence and the maximum structural response. Earthquake Engineering and Structural Dynamics,26, 881-894.

Navarro, M., García-Jerez, A., Alcalá, F. J., Vidal, F., \& Enomoto, T. (2014). Local site effect microzonation of Lorca town (SE Spain). Bulletin of Earthquake Engineering,12, 1933-1959.

Ordaz, M., \& Aguilar, A. (2015). CRISIS2015 program for computing seismic hazard. Retrieved January 1, 2017, from https://sites.google.com/site/codecrisis2015/

Otani, S. (1974). Inelastic analysis of RC frame structures. ASCE Journal of Structural Division,100, 1433-1449.

Park, Y. J., \& Ang, A. H. S. (1985). Mechanistic seismic damage model for reinforced concrete. Journal of Structural Engineering,111, 722-739.

Park, Y. J., Ang, A. H. S., \& Kwei-Wen, Y. (1985). Seismic damage analysis of reinforced concrete buildings. Journal of Structural Engineering,111, 740-757.

Poursha, M., Khoshnoudian, F., \& Moghadam, A. S. (2009). A consecutive modal pushover procedure for estimating the seismic demands of tall buildings. Engineering Structures,31, 591-599.

Pujades, L. G., Barbat, A. H., González-Drigo, R., Avila, J., \& Lagomarsino, S. (2012). Seismic performance of a block of buildings representative of the typical construction in the Eixample district in Barcelona (Spain). Bulletin of Earthquake Engineering,10, 331-349.

Pujades, L.G., Vargas, Y.F., Barbat, A.H., \& González-Drigo, J.R. (2015). Parametric model for capacity curves. Bulletin of earthquake engineering,13, 1347-1376.

Reyes, J. C., \& Chopra, A. K. (2010). Three-dimensional modal pushover analysis of building subjected to two components of ground motions, including its evaluation for tall buildings. Earthquake Engineering and Structural Dynamics,40, 789-806.

Reyes, J. C., \& Chopra, A. K. (2011). Evaluation of three-dimensional modal pushover analysis for unsymmetric-plan buildings subjected to two components of ground motion. Earthquake Engineering and Structural Dynamics,40, 1475-1494.

Reyes, J. C., \& Kalkan, E. (2015). Significance of rotating ground motions on behavior of symmetricand asymmetric-plan structures: Part I. Single-story structures. Earthquake Spectra,31, 1591-1612.

Rigato, A. B., \& Medina, R. A. (2007). Influence of angle of incidence on seismic demands for inelastic single-storey structures subjected to bi-directional ground motions. Engineering Structures,29, 2593-2601.

Rueda, J., Dreger, D., Garcia Blanco, R. M., \& Mezcua, J. (2014). Directivity detection and source properties of the 11 May $2011 \mathrm{Mw}$ 5.2 Lorca, Spain, Earthquake. Bulletin of the Seismological Society of America,104, 1735-1749.

Sharpe, R.D. (1974). The seismic response of inelastic structures (PhD Thesis). Department of Civil engineering, University of Canterbury, 1974.

Satyarno, I. (2000). Pushover analysis for the seismic assessment of reinforced concrete buildings (PhD Thesis). Department of Civil engineering, University of Canterbury, 1974.

Torbol, M., \& Shinozuka, M. (2012). The directionality effect in the seismic risk assessment of highway networks. Structure and Infrastructure Engineering,10, 175-188.

Vargas, Y. F., Pujades, L. G., Barbat, A. H., \& Hurtado, J. E. (2012). Computational methods in stochastic dynamics, Vol. 2. Netherlands: Springer 


\section{List of figures}
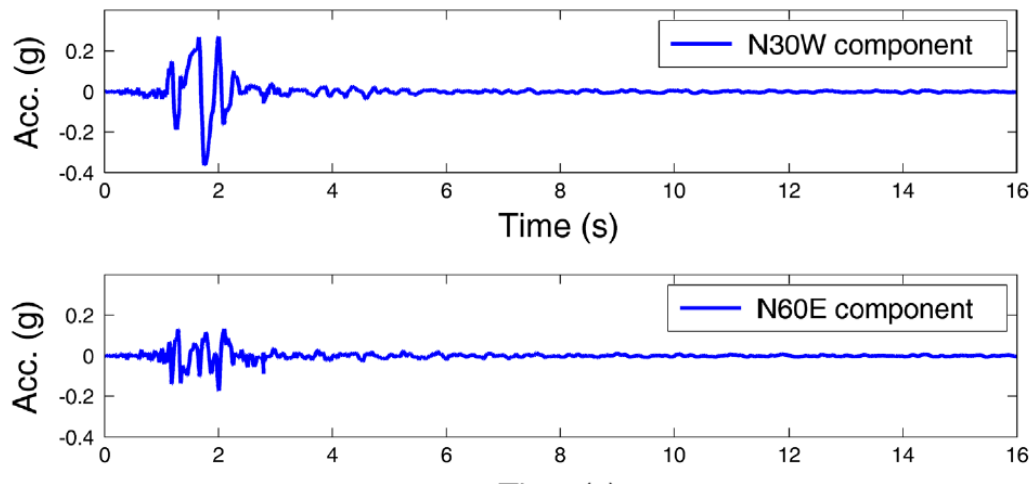

Time (s)

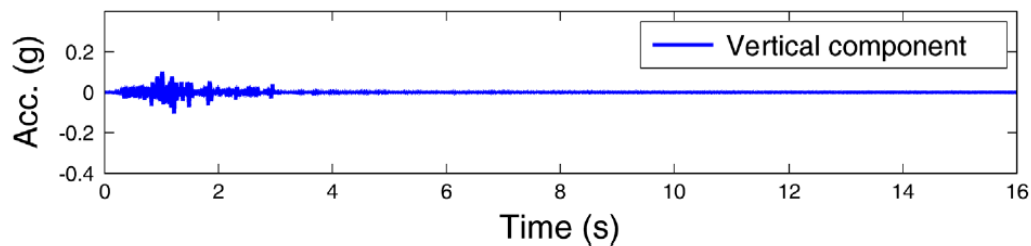

Figure 1. Recorded accelerograms of the May 2011 Lorca earthquake.

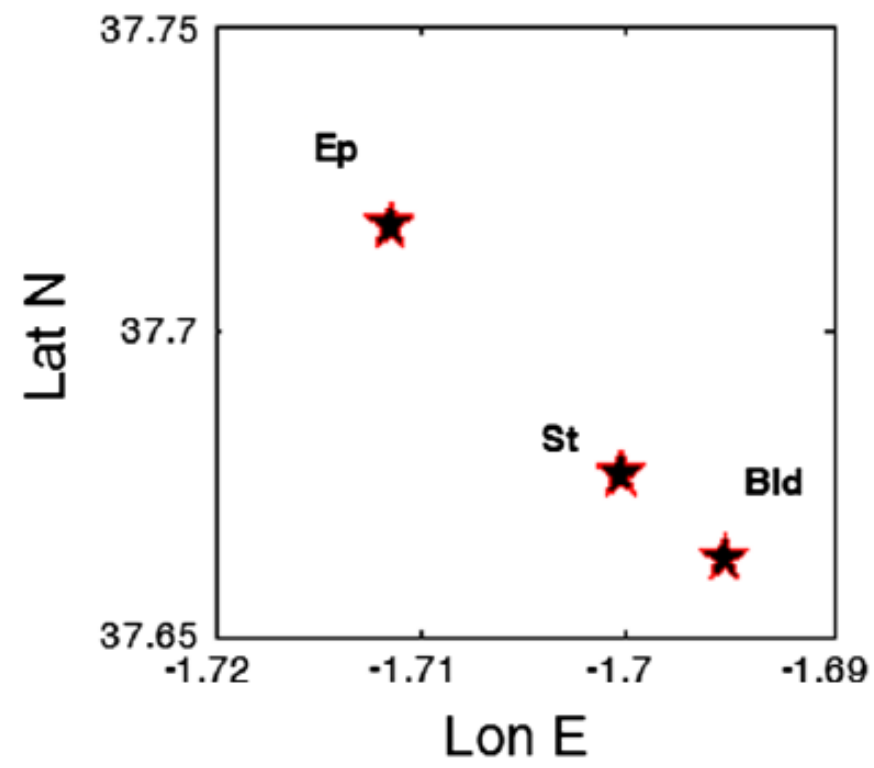

Figure 2. Location of epicentre (EP), Station (ST) and building (Bld). 


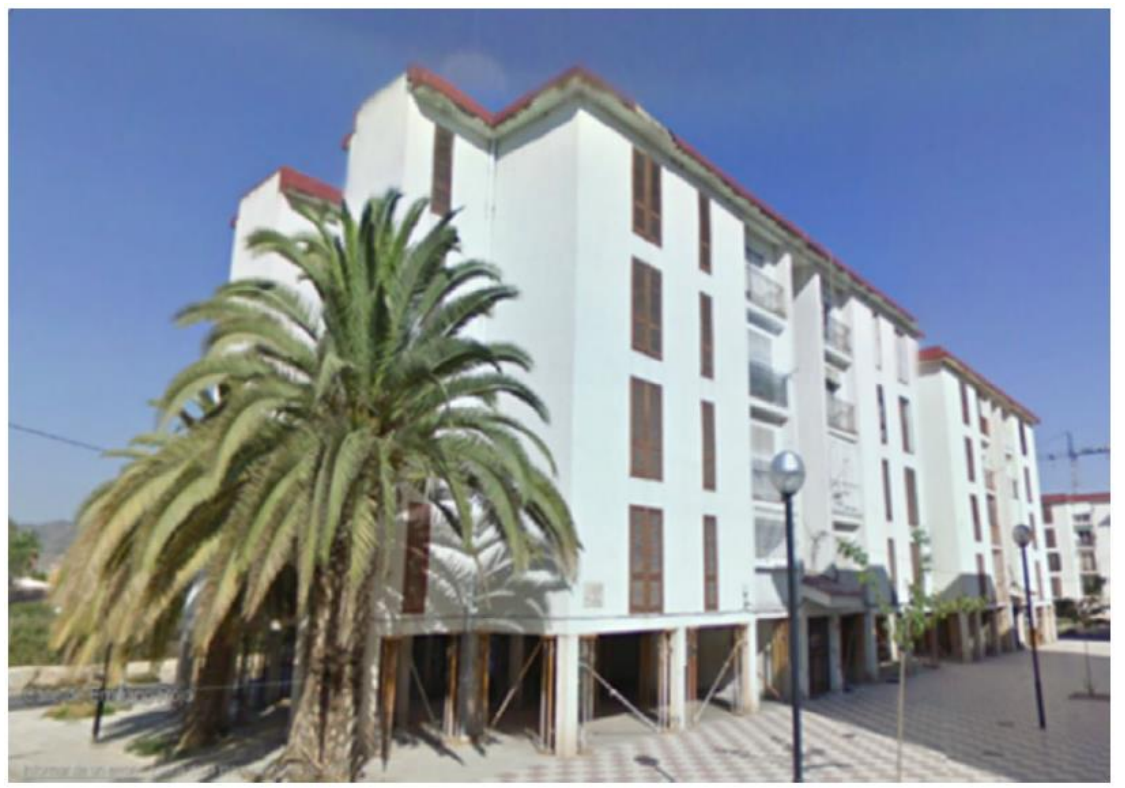

Figure 3. Buildings located in the San Fernando neighbourhood of the city of Lorca, Spain, affected by the earthquake.

(a)

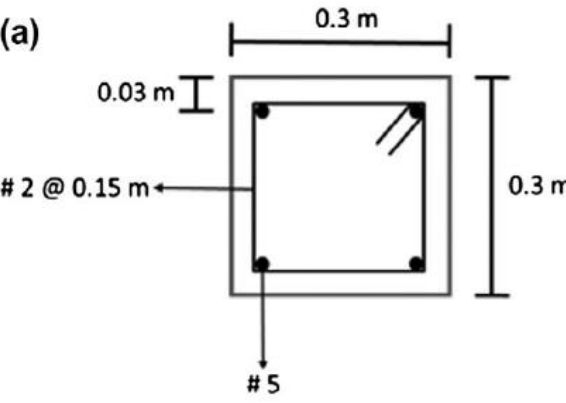

(b)

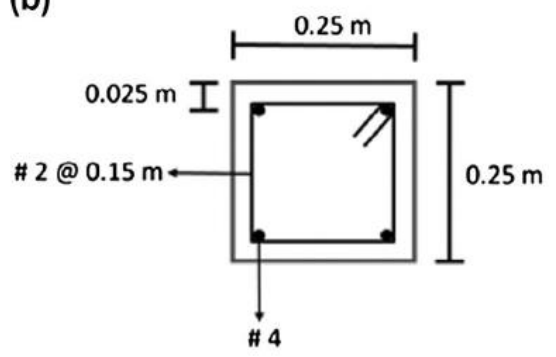

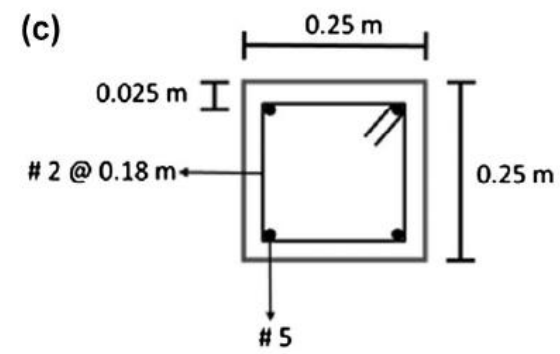

Figure 4. Cross sections of the structural elements: (a) typical column of the first floor, (b) typical column of the superior floors and (c) typical beam. 

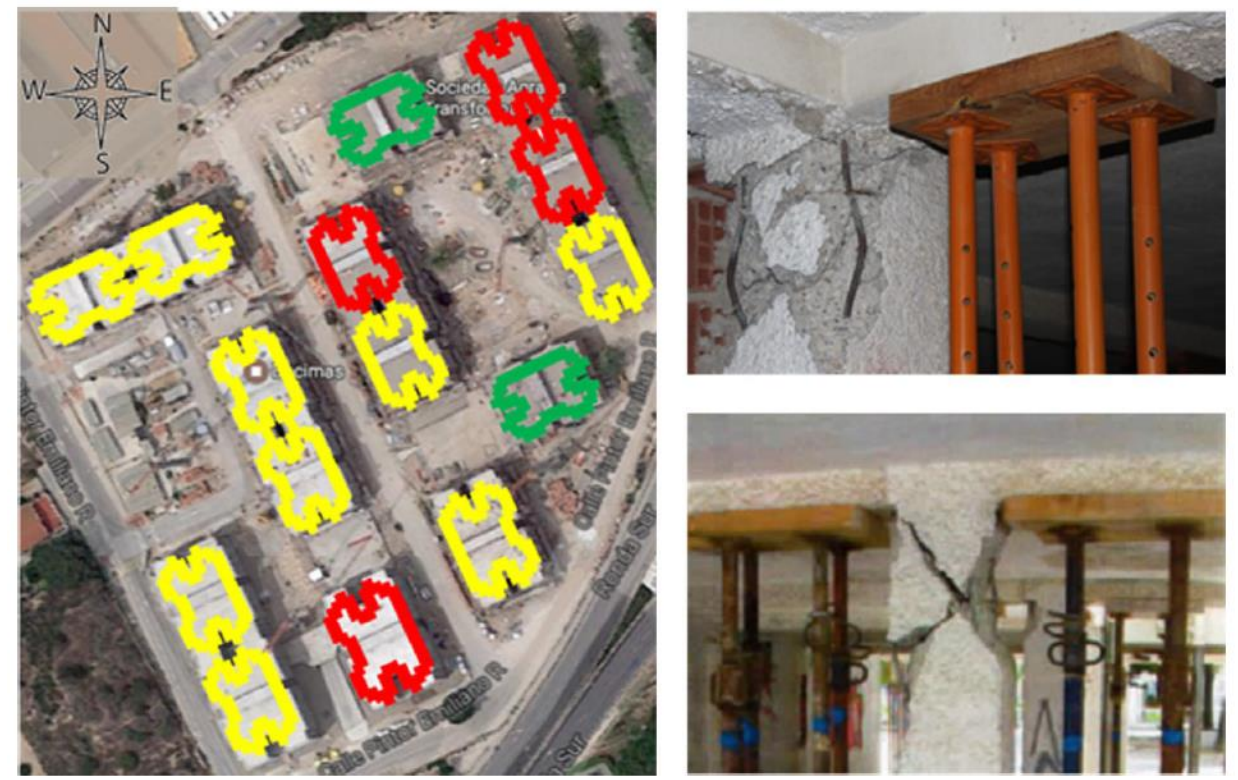

Figure 5. Plan view of the buildings located in San Fernando neighbourhood affected by the Lorca earthquake. Green colour indicates that the building was not damaged; yellow colour means that the damage is reparable and red colour indicates that the building is holding extensive damage and that there is risk of collapse.

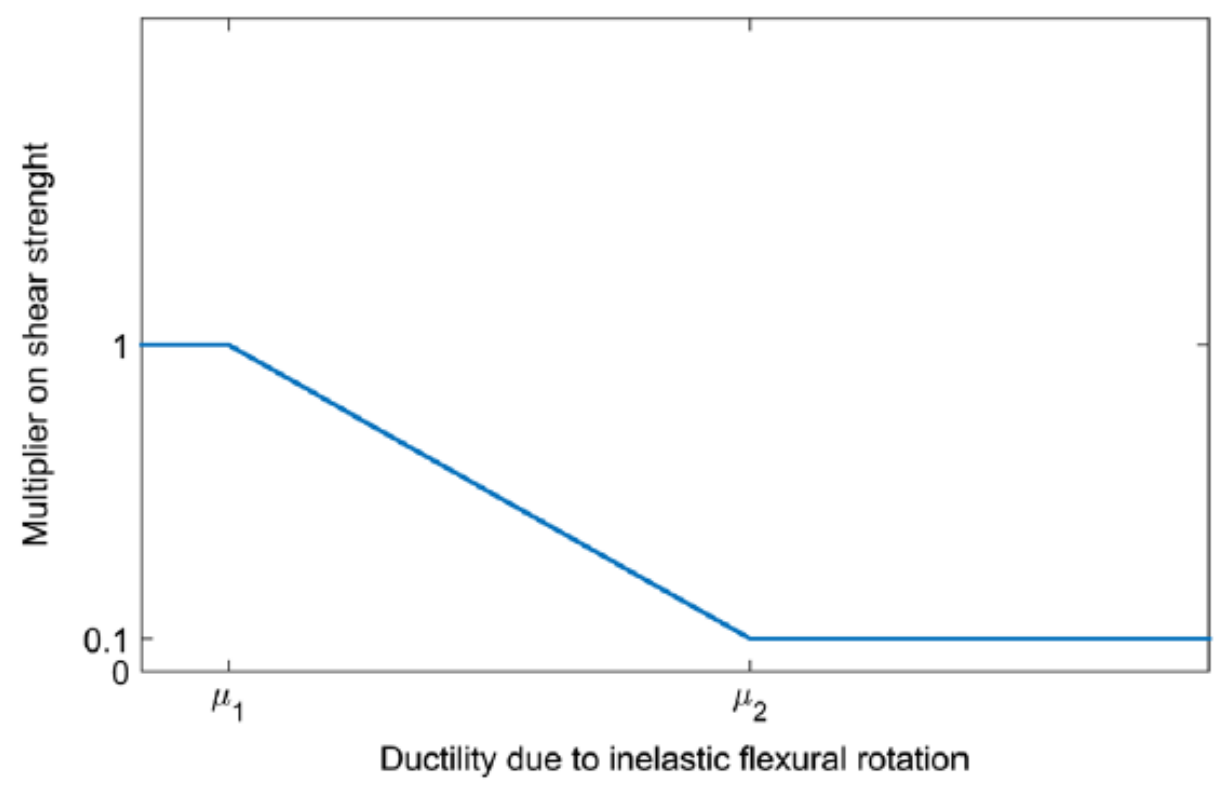

Figure 6. Shear strength degradation due to inelastic flexural rotation, Carr (2000) 

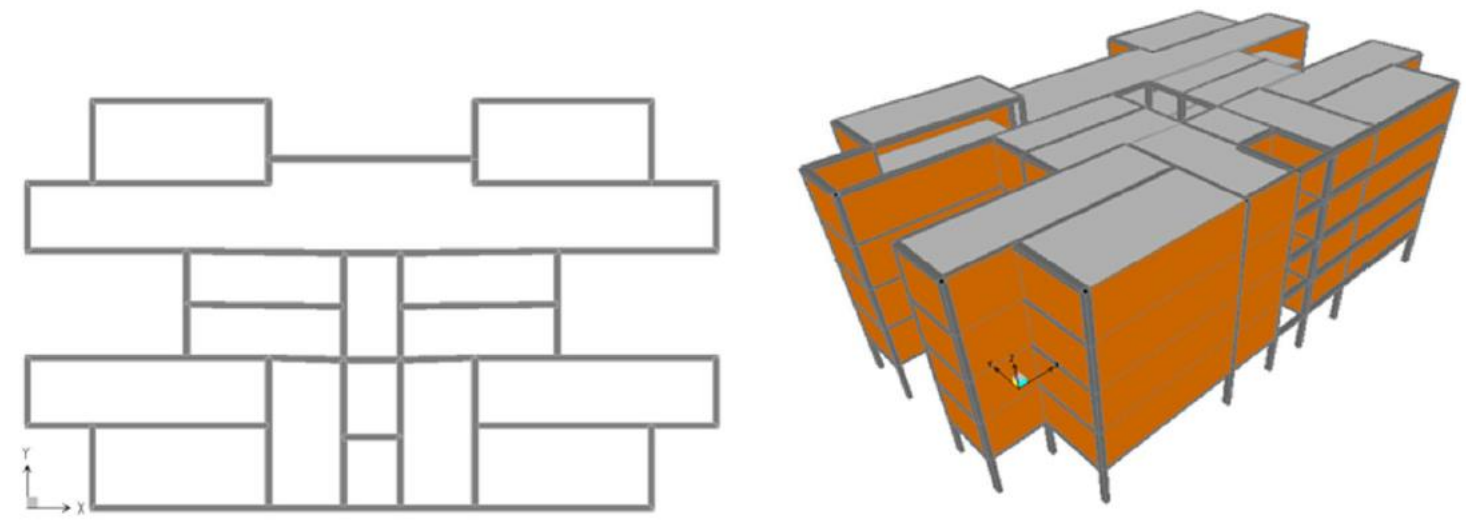

Figure 7. (a) Plan view of the model and (b) 3D view of the model.

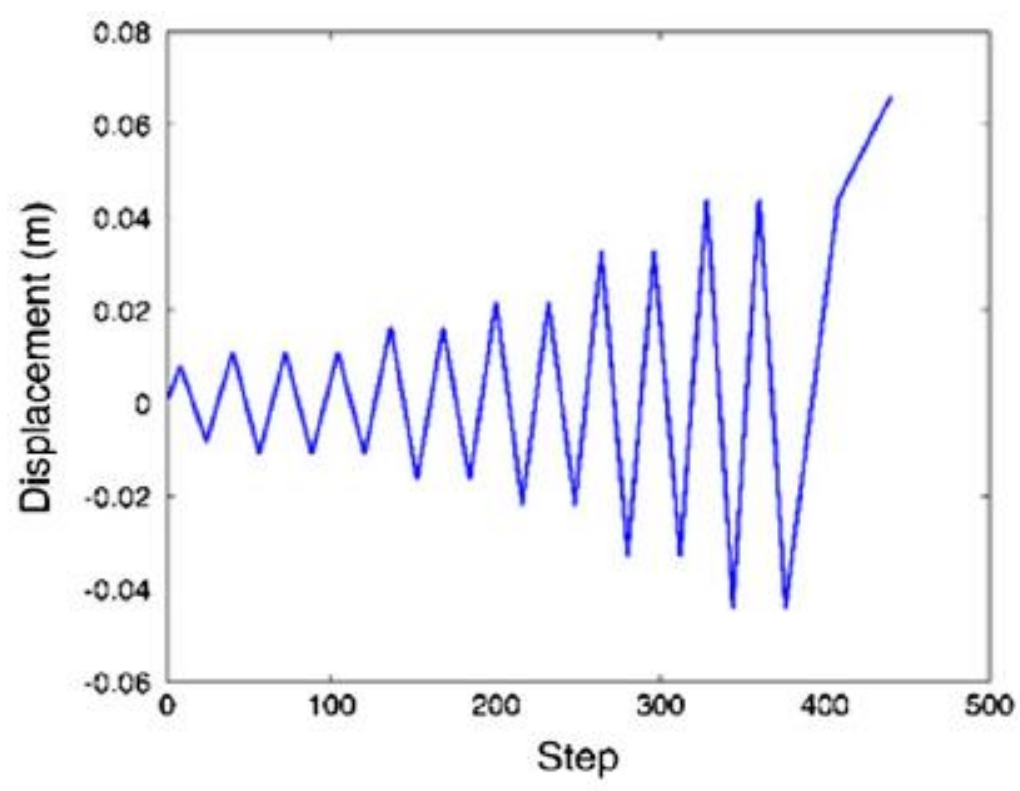

Figure 8. Horizontal cyclic displacement history.

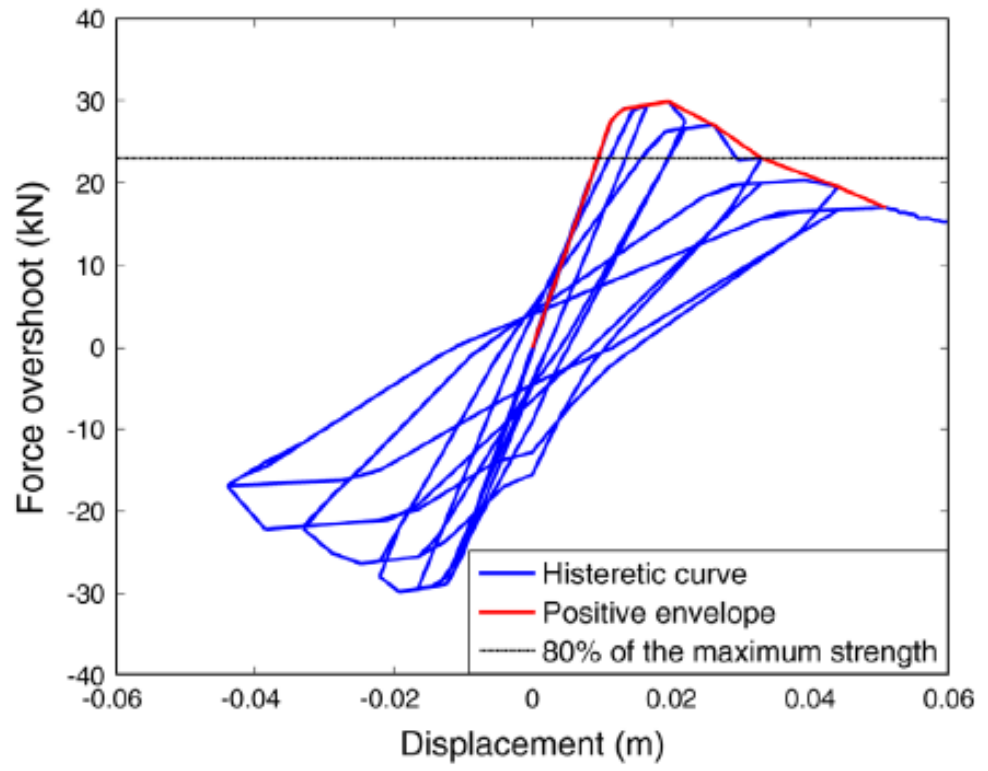

Figure 9. Hysteretic curve of a typical column of the studied building. 

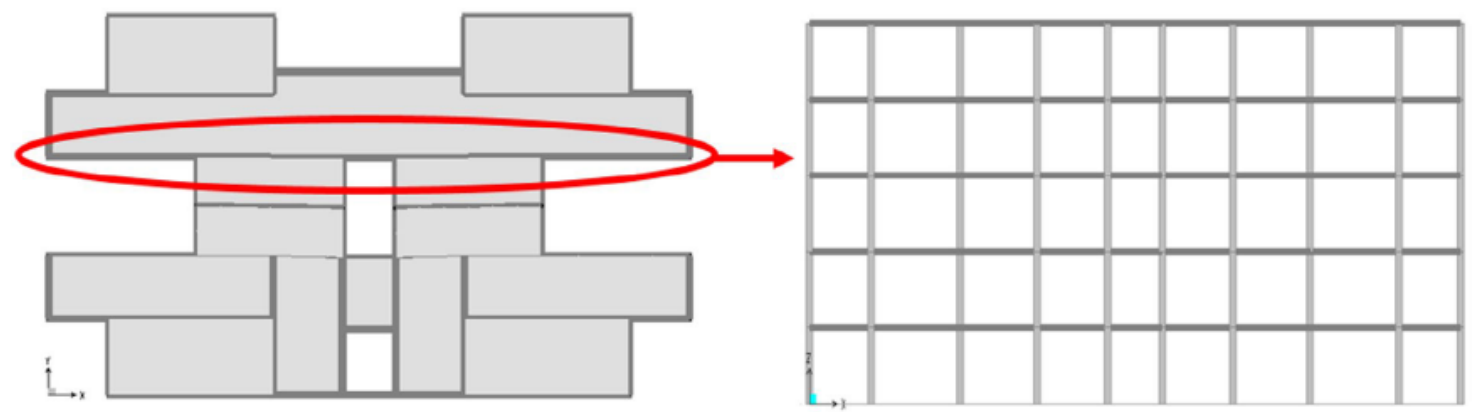

Figure 10. 2D frame model used to analyse the influence of the spatial variability.

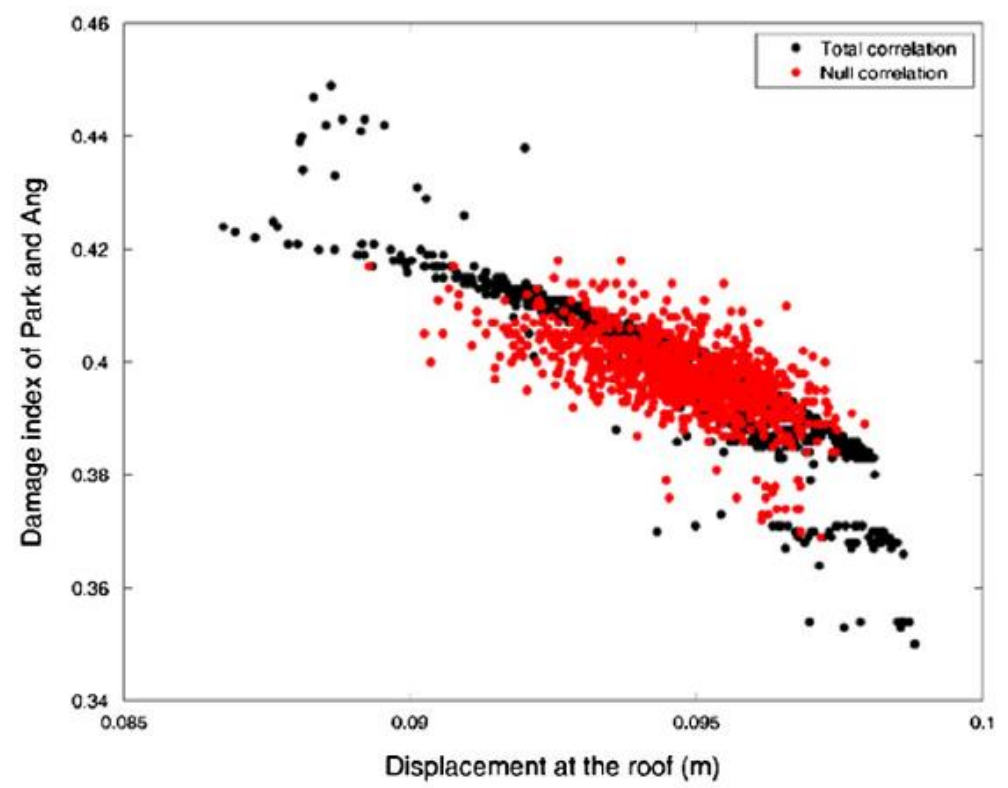

Figure 11. Damage index of Park and Ang as a function of the maximum displacement at the roof. Comparison of the total and null hypothesis for the sample correlation.

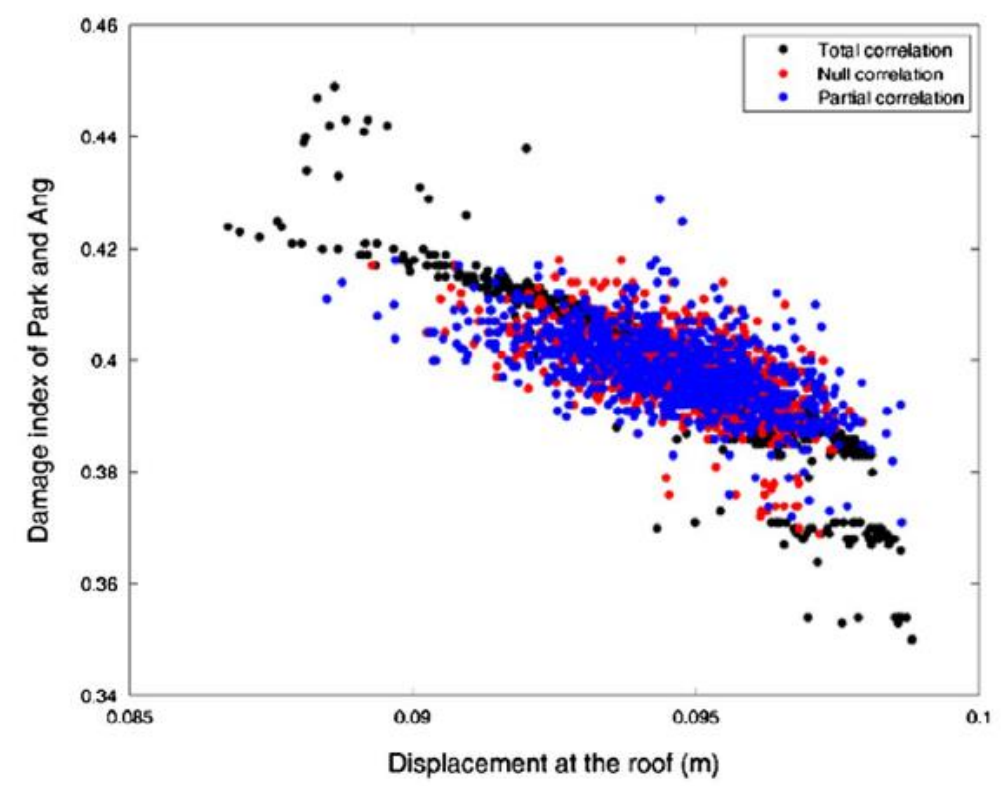

Figure 12. Damage index of Park and Ang as a function of the maximum displacement at the roof. Comparison of the total, null and partial correlation hypotheses. 
(a)

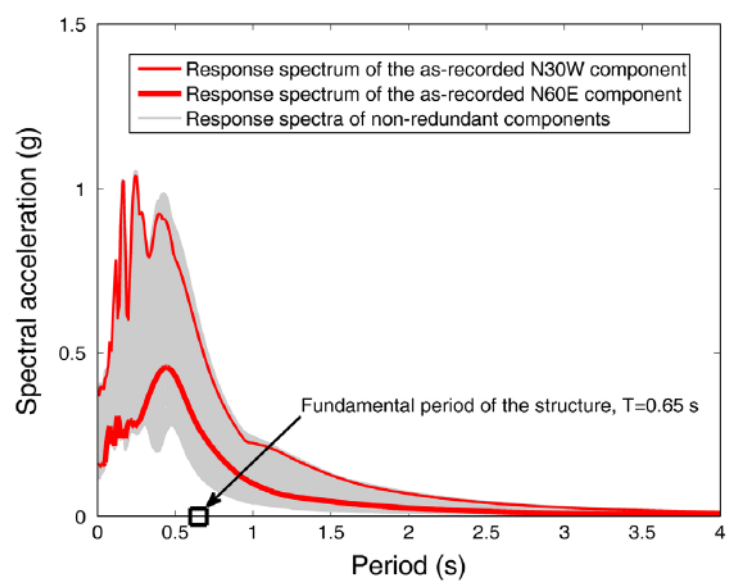

(b)

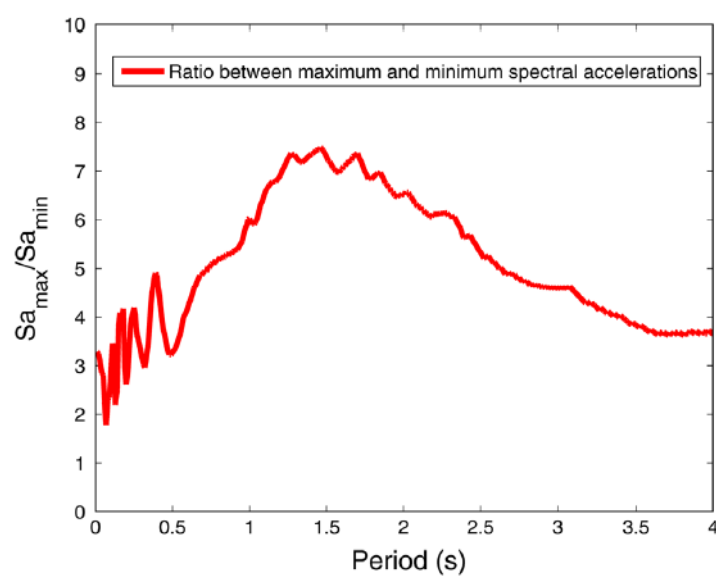

Figure 13. Acceleration response spectra obtained after rotating the acceleration record of the Lorca earthquake. For the mean fundamental period of the building, the spectral acceleration may vary approximately 5 times. The coefficient of variation of the fundamental period is .12.

(a)

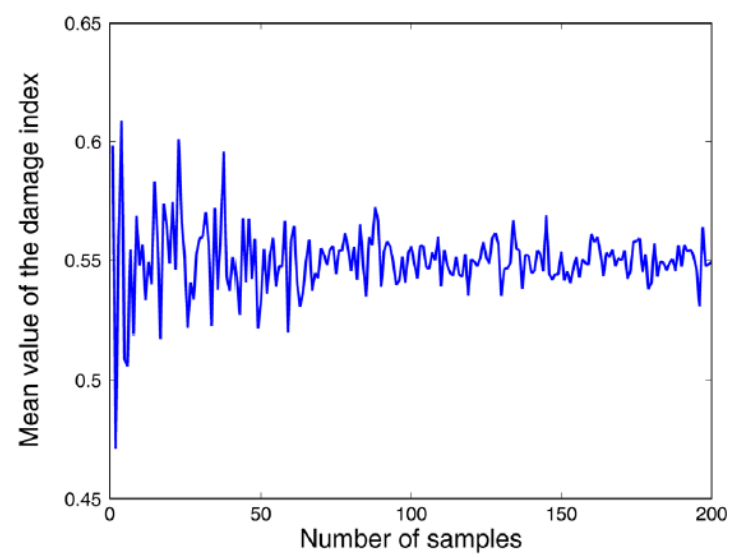

(b)

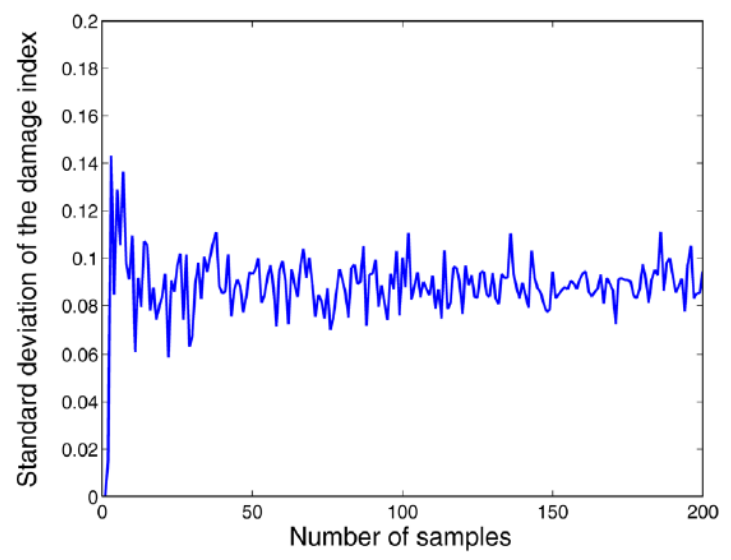

Figure 14. Evolution of the first two moments, mean and standard deviation, of the Gaussian distribution of the damage index as functions of the number of samples.

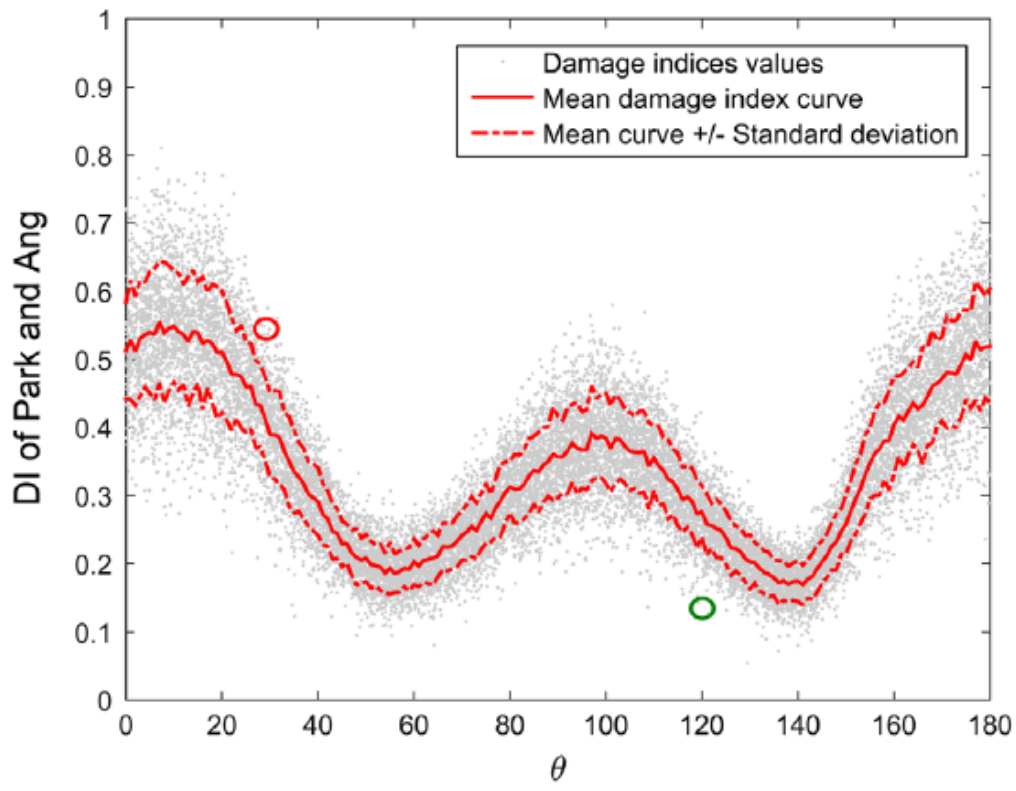


Figure 15. Variation of the damage index considering the angle of rotation of the earthquake and the uncertainties associated to the mechanical properties of the materials.

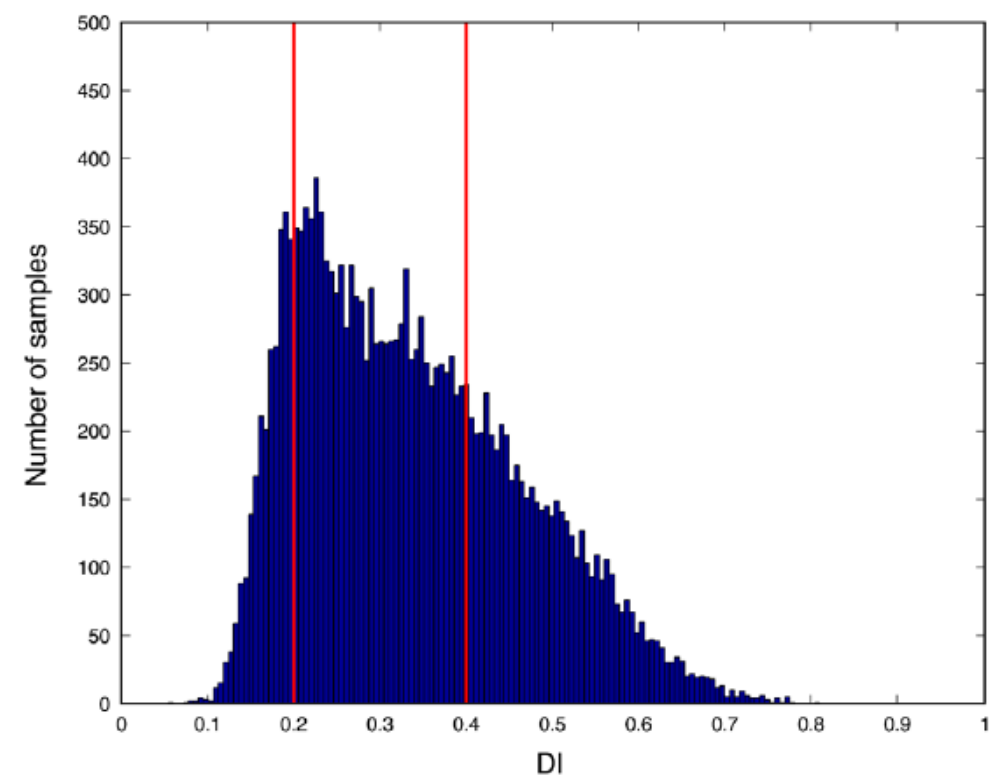

Figure 16. Histogram of the expected values of the Park and Ang damage index (DI). Damage thresholds corresponding to values of .5 (not repairable damage) and .2 (slight damage) are also depicted with red lines.

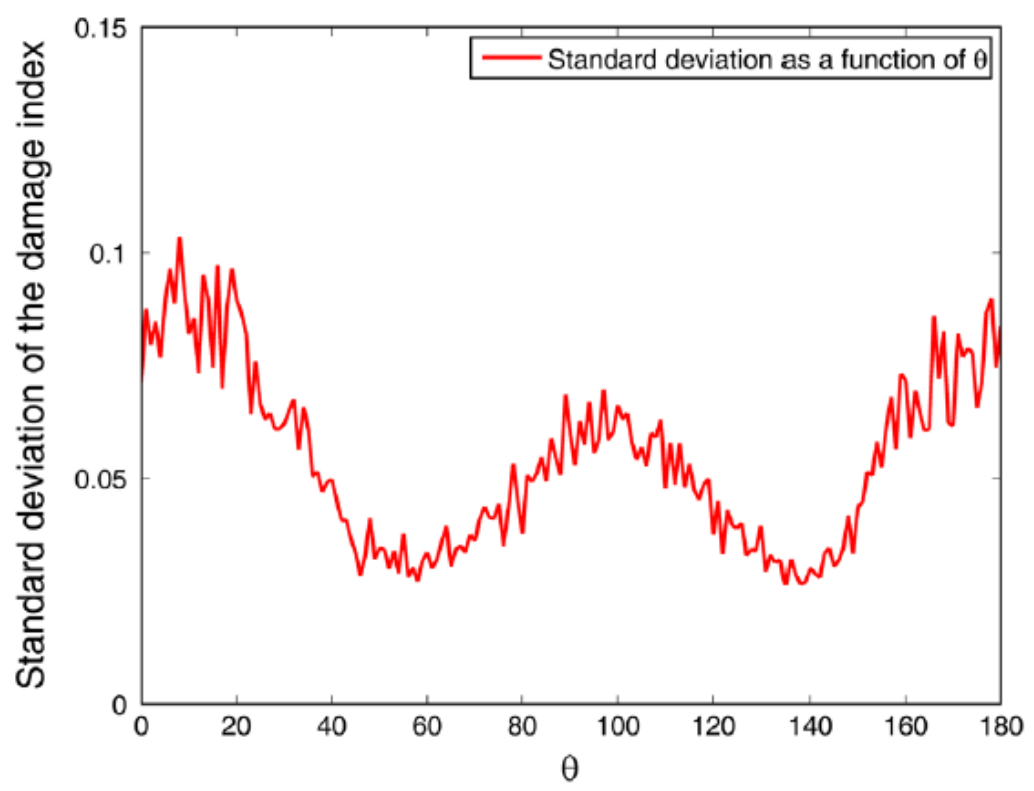

Figure 17. Standard deviation of the damage index distribution as a function of $\theta$. 


\section{List of tables}

Table 1. Geographical coordinates of the Epicentre (Ep), Station (St) and the San Fernando neighbourhood (Bld).

\begin{tabular}{lcccc}
\hline & Lat N $\left({ }^{\circ}\right)$ & Lon W $\left({ }^{\circ}\right)$ & Ep Az $\left({ }^{\circ}\right)$ & Ep Dist $(\mathrm{km})$ \\
\hline Ep & 37.7175 & 1.7114 & - & - \\
St & 37.6767 & 1.7002 & 167.7 & 4.6 \\
Bld & 37.6628 & 1.6952 & 166.8 & 6.2 \\
\hline
\end{tabular}

Table 2. Statistical moments of the mechanical properties of the materials considered herein.

\begin{tabular}{lcc}
\hline Variable & $\mu_{x}(\mathrm{kPa})$ & $\sigma_{x}(\mathrm{kPa})$ \\
\hline$f_{c}$ & 21,000 & 2100 \\
$f y$ & 500,000 & 50,000 \\
\hline
\end{tabular}

Table 3. Characteristic values of the random variables analysed.

\begin{tabular}{lcccccc}
\hline & $D I_{t c}$ & $D I_{n c}$ & $D I_{p c}$ & $\delta_{t c}$ & $\delta_{n c}$ & $\delta_{p c}$ \\
\hline Mean & .3975 & .3977 & .3984 & .0948 & .0947 & .0946 \\
Standard deviation & .0131 & .0067 & .0067 & .0022 & .0013 & .0016 \\
Coefficient of variation & .0330 & .0167 & .0169 & .0228 & .0140 & .0167 \\
\hline
\end{tabular}

